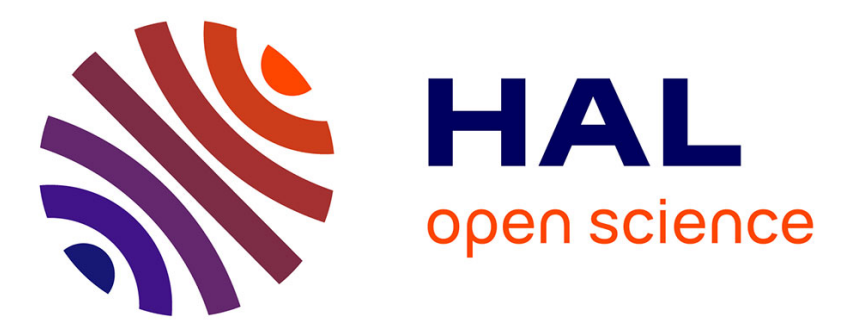

\title{
Liquorice and glycyrrhetinic acid increase DHEA and deoxycorticosterone levels by inhibiting adrenal SULT2A1 activity
}

\author{
E.A.S. Al-Dujaili, C.J. Kenyon, M.R. Nicol, J.I. Mason
}

\section{To cite this version:}

E.A.S. Al-Dujaili, C.J. Kenyon, M.R. Nicol, J.I. Mason. Liquorice and glycyrrhetinic acid increase DHEA and deoxycorticosterone levels by inhibiting adrenal SULT2A1 activity. Molecular and Cellular Endocrinology, 2011, 336 (1-2), pp.102. 10.1016/j.mce.2010.12.011 . hal-00675792

\section{HAL Id: hal-00675792 \\ https://hal.science/hal-00675792}

Submitted on 2 Mar 2012

HAL is a multi-disciplinary open access archive for the deposit and dissemination of scientific research documents, whether they are published or not. The documents may come from teaching and research institutions in France or abroad, or from public or private research centers.
L'archive ouverte pluridisciplinaire HAL, est destinée au dépôt et à la diffusion de documents scientifiques de niveau recherche, publiés ou non, émanant des établissements d'enseignement et de recherche français ou étrangers, des laboratoires publics ou privés. 


\section{Accepted Manuscript}

Title: Liquorice and glycyrrhetinic acid increase DHEA and deoxycorticosterone levels in vivo and in vitro by inhibiting adrenal SULT2A1 activity

Authors: E.A.S. Al-Dujaili, C.J. Kenyon, M.R. Nicol, J.I. Mason

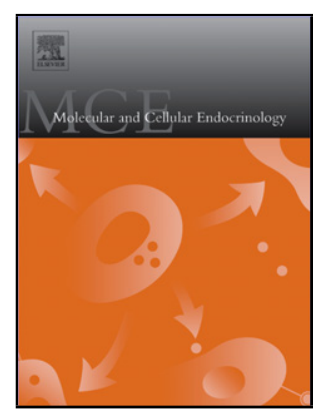

PII:

DOI:

Reference:

S0303-7207(10)00574-5

To appear in: $\quad$ Molecular and Cellular Endocrinology

Received date: $\quad 30-8-2010$

Revised date: $\quad 1-12-2010$

Accepted date: $\quad$ 6-12-2010

Please cite this article as: Al-Dujaili, E.A.S., Kenyon, C.J., Nicol, M.R., Mason, J.I., Liquorice and glycyrrhetinic acid increase DHEA and deoxycorticosterone levels in vivo and in vitro by inhibiting adrenal SULT2A1 activity, Molecular and Cellular Endocrinology (2010), doi:10.1016/j.mce.2010.12.011

This is a PDF file of an unedited manuscript that has been accepted for publication. As a service to our customers we are providing this early version of the manuscript. The manuscript will undergo copyediting, typesetting, and review of the resulting proof before it is published in its final form. Please note that during the production process errors may be discovered which could affect the content, and all legal disclaimers that apply to the journal pertain. 
Liquorice and glycyrrhetinic acid increase DHEA and deoxycorticosterone levels in vivo and in vitro by inhibiting adrenal SULT2A1 activity

\section{EAS Al-Dujaili ${ }^{1 \#}$, CJ Kenyon ${ }^{2}$, MR Nicol ${ }^{3}$, JI Mason ${ }^{3}$}

${ }^{1}$ Department of Dietetics, Nutrition and Biological Sciences, Queen Margaret University, Edinburgh, UK

${ }^{2}$ Centre for Cardiovascular Science, The Queen's Medical Research Institute, University of Edinburgh, Edinburgh, UK

${ }^{3}$ Centre for Reproductive Biology, The Queen's Medical Research Institute, University of Edinburgh, Edinburgh, UK

\#Correspondence to: Dr Emad Al-Dujaili,

Department of Dietetics, Nutrition and Biological Sciences

Queen Margaret University Edinburgh

Queen Margaret University Drive

Musselburgh, East Lothian

EH21 6UU

United Kingdom

Tel: 0044-1314740000

Fax: 0044-1314740001

E-mail: ealdujaili@qmu.ac.uk 


\begin{abstract}
The mineralocorticoid effects of liquorice are mediated by the inhibitory effects of one of its active components glycyrrhetinic acid on 11ß-hydroxysteroid dehydrogenase type 2 . However, liquorice is reputed to have many medicinal properties and also contains a number of other potentially biologically active compounds. Here we have investigated the wider effects of oral liquorice on steroidogenesis focussing particularly on possible inhibitory effects of glycyrrhetinic acid on adrenal sulfotransferase activity.

Salivary steroids were profiled by ELISA in groups of normal male and female volunteers after consuming either liquorice-containing or non-liquorice-containing confectionary for one week. Cortisol and cortisone levels reflected expected inhibition of $11 \beta$-hydroxysteroid dehydrogenase type 2 by glycyrrhetinic acid. Salivary aldosterone was decreased but deoxycorticosterone, dehydroepiandrosterone and testosterone were increased. To assess whether glycyrrhetinic acid directly affected steroidogenesis, free and conjugated steroids were measured in incubates of adrenocortical H295 cells, firstly, in the presence or absence of forskolin and, secondly, with radiolabeled deoxycorticosterone or dehydroepiandrosterone. Glycyrrhetinic acid inhibited cortisone and enhanced cortisol synthesis consistent with $11 \beta$ hydroxysteroid dehydrogenase type 2 inhibition. Basal and forskolin-stimulated synthesis of deoxycorticosterone and dehydroepiandrosterone conjugates were also inhibited in a dosedependent manner; glycyrrhetinic acid inhibited the conjugation of deoxycorticosterone and dehydroepiandrosterone with IC50 values of $7 \mu \mathrm{M}$. Inhibition of deoxycorticosterone and dehydroepiandrosterone conjugation was apparent within 4 h of starting glycyrrhetinic acid treatment and was not associated with changes in the expression of SULT mRNA. SULT2A1 encodes the enzyme sulfotransferase $2 \mathrm{~A} 1$ which is responsible for the sulfonation of deoxycorticosterone and dehydroepiandrosterone as well as pregnenolone and 17-
\end{abstract}


hydroxypregnenolone in human adrenal glands. We suggest that the glycyrrhetinic acid constituent of liquorice increases circulating and, thereby, salivary levels of unconjugated deoxycorticosterone and dehydroepiandrosterone by inhibiting their conjugation at source within the adrenal cortex. This effect may contribute to the mineralocorticoid actions of glycyrrhetinic acid and gives substance to claims that liquorice also has androgenic properties.

Keywords: SULT2A1; DHEA; Deoxycorticosterone; Liquorice; Glycyrrhetinic acid
Abbreviations
$11 \mathrm{HSD}=11 \beta$-hydroxysteroid dehydrogenase
$\mathrm{DOC}=$ deoxycorticosterone
DHEA $=$ dehydroepiandrosterone
ELISA $=$ enzyme linked immunosorbant assay.
$\mathrm{GA}=$ glycyrrhetinic acid
SULT2A1 = hydroxysteroid sulfotransferase $2 \mathrm{~A} 1$
RAAS $=$ renin-angiotensin-aldosterone system 


\section{Introduction}

The hypertensive effects of liquorice and its active constituent glycyrrhetinic acid (GA) have been widely investigated (Conn et al., 1968; Farese et al., 1991), and attributed mainly to competitive inhibition of $11 \beta$-hydroxysteroid dehydrogenase type 2 (11HSD2) (Walker and Edwards, 1994). This enzyme is expressed in mineralocorticoid target tissues (eg colon and renal collecting duct) and normally serves to prevent glucocorticoid hormones from occupying mineralocorticoid receptors by converting biologically active cortisol to inactive cortisone. When 11HSD2 is inhibited, endogenous glucocorticoids act as mineralocorticoid hormones. However, liquorice root has been used medicinally for many years to treat a variety of conditions [eg dry cough, asthma, thirst, sterilility, fever, digestive problems (Davis and Morris, 1991; Hussain, 2003)] and, more recently by the body building fraternity, to increase muscle mass (www.bodybuilder.com/store/now/lic/html; www.crticalbench.com/licorice-root-supplement-review.htm). These properties are not necessarily mediated by GA and could be due to one or more of the many other biologically active constituents of liquorice root (eg flavonoids, isoflavonoids, polysaccharides, coumarins, sterol, phytoestrogens, volatile oils, glycyramarine as well as vitamins, minerals and amino acids (Asl and Hosseinzadeh, 2008; Lee et al.; Shibata, 2000).

In addition to effects on glucocorticoid metabolism GA is thought to have other endocrine effects. For example, there have been several reports (Armanini et al., 1999; Takahashi et al., 1988; Takeuchi et al., 1991) albeit disputed (Josephs et al., 2001) that GA and glycyrrhyzic acid (GZ) inhibit 17-20-lyase and 17-hydroxysteroid dehydrogenase activities thereby reducing testosterone synthesis in males and females by blocking the conversion of 17 hydroxyprogesterone (17-OHP) to androstenedione and then the conversion of androstenedione to testosterone. 
Here we have gained a more comprehensive view of the effects of liquorice and GA on adrenal steroidogenesis by assaying mineralocorticoids, glucocorticoids and androgens in vivo in saliva of normal volunteers. We and others have found salivary steroid levels to be useful indicators of circulating plasma concentrations. (Atherden et al., 1985; Conway et al., 2007; Groschl, 2009). Samples can be readily obtained non-invasively from patients and volunteers without the need of supervision. The effects of GA on corticosteroidogenesis have been modelled using a multipotent human adrenocortical cell line (H295) (Rainey et al., 2004). These cells secrete aldosterone, cortisol and DHEA in response to a variety of trophic factors although responsiveness to $\mathrm{ACTH}$ is impaired due to an abnormal melanocortin receptor. This problem is bipassed by using forskolin to raise levels of cyclic AMP.. Based on our preliminary findings we have developed a hypothesis that GA influences circulating levels of adrenocortical derived steroid hormones by inhibiting their conjugation. In particular we have focussed on the hydroxysteroid sulfotransferase SULT2A1, an enzyme responsible for the sulfonation of DHEA, DOC and other steroids which are expressed in human adrenocortical tissue and H295 cells (Rainey et al., 2002; Strott, 2002; Kumar et al., 2009). 


\section{Materials and Methods}

\subsection{Human study}

The effects of dietary liquorice on salivary steroid hormone levels were tested in groups of 10 males and 10 female volunteers in a study that was approved by Queen Margaret University's Ethical Committee. Exclusion criteria were high (systolic $>140 \mathrm{mmHg}$ ) or low (diastolic $<60 \mathrm{mmHg}$ ) blood pressure, treatment with drugs affecting blood pressure or endocrine functions (including oral contraceptives), menstrual disorders, allergy to liquorice, and a history of kidney or liver disease.

The study followed a cross-over design to compare the effects of liquorice-containing confectionery (contents: wheat flour, glucose syrup, modified maize starch, 3\% liquorice extract, caramel, salt, caramel flavouring) and non-liquorice confectionery of the same sugar content and calorific value (contents: sugar, glucose syrup, water, maize starch, beef gelatine, flavourings, cochineal colour). Volunteers were asked to consume daily $100 \mathrm{~g}$ of nonliquorice confectionery for 1 week, followed by a wash period of 3 days, and then the liquorice confectionary for another week. Female participants were tested during the follicular phase of the menstrual cycle with dayl of the test corresponding to the start of the cycle. Body weight, height and blood pressure when lying down were recorded before and at the end of each arm of the study. Mean participant age was $23.12 \pm 5.6$ years and BMI was $23.26 \pm 4.37 \mathrm{~kg} / \mathrm{m}^{2}$. There was no significant change in BMI with either arm of the study. Participants were given very detailed instructions on how to collect and store saliva samples. On days 7 and 10 of treatment, participants provided three saliva samples: (i) 30 minutes after waking $(8.00-9.00 \mathrm{~h})$; (ii) mid-morning between 11 and 13.00h; (iii) in the evening between 19.00 and $20.00 \mathrm{~h}$. 


\subsection{Salivary steroids}

Coded saliva samples were stored at $-20^{\circ} \mathrm{C}$ prior to assay for cortisol, cortisone, aldosterone, deoxycorticosterone (DOC), testosterone and dehydroepiandrosterone (DHEA). Steroids were extracted from saliva samples with diethyl ether and measured using sensitive and specific ELISAs modified from methods previously described (Al-Dujaili 2006; AlDujaili et al., 2009a; Al-Dujaili et al., 2009b). Briefly, 0.5mL of saliva was vortexed with $5 \mathrm{~mL}$ diethylether for $10 \mathrm{~min}$ then placed in a $-80 \mathrm{C}$ freezer. The ether was then decanted from the frozen aqueous layer into a glass tube and evaporated to dryness under nitrogen. The residue was reconstituted in $0.5 \mathrm{~mL}$ of assay buffer. Free and conjugated levels of DHEA, DOC and other steroids were measured separately in pooled $0.5 \mathrm{~mL}$ aliquots of male saliva after fractionation using C18 Sep-Pak cartridges (Waters Ltd, Elstree, Hertfordshire, UK). Conjugated steroids were hydrolysed prior to assay by incubation with extracts of Helix pomatia, then extracted with ether and assayed.

\subsection{In vitro studies}

NCI-H295 cells (CRL-2128, ATCC, Rockville, MD, USA) were cultured in Dulbecco's modified Eagle's medium /F12 (DMEM/F12, Invitrogen, Paisley, Renfrew, UK) supplemented with $2 \%$ cosmic calf serum (Hyclone, Thermo Scientific, Cramlington, UK), 5 $\mu \mathrm{g} / \mathrm{mL}$ insulin, $5 \mu \mathrm{g} / \mathrm{mL}$ transferrin and $5 \mathrm{ng} / \mathrm{mL}$ sodium selenite (as $1 \%$ ITS, Invitrogen) at $37^{\circ} \mathrm{C}$ with $5 \% \mathrm{CO}_{2}-95 \%$ air. Cells were seeded at 500,000 cells/well in 6-well plates. For experiments, cells were serum-deprived overnight and incubated for up to $24 \mathrm{~h}$ with various concentrations of glycyrrhetinic acid $(0-50 \mu \mathrm{M})$ in the presence or absence of forskolin $(10$ $\mathrm{mM}$ ). In some experiments steroid conjugation was measured directly by incubating cells 
with $\left[{ }^{3} \mathrm{H}\right]$-DHEA (GE Healthcare, Amersham Bucks, UK) and $\left[{ }^{3} \mathrm{H}\right]-$ DOC (MP Biomedicals, Solon, Ohio, USA). The medium was removed and stored at $-80^{\circ} \mathrm{C}$ for steroid analysis; remaining cells were lyzed and RNA extracted using RNeasy mini-kits (Qiagen, Crawley, West Sussex, UK). Steroids were extracted from the medium using C18 Sep-Pak cartridges; conjugated and free steroids were eluted separately with $40 \%$ and $100 \%$ aqueous methanol respectively. Radioactivity in free and conjugated fractions was measured by scintillation counting. Absolute levels of steroids were measured by ELISA; conjugated steroids were hydrolysed with Helix pomatia prior to assay.

\subsection{Real time PCR assays}

RNA was extracted using Qiagen RNeasy Mini kit and genomic DNA was excluded by DNase treatment of samples, on-column, with the RNase free DNase set (Qiagen) according to supplier's protocol. RNA purity and quantification were assessed spectrophotometrically (Nanodrop model ND-1000, Nanodrop Technologies Inc, Wilmington, DE, USA). mRNA (200ng) was reversed transcribed using RT-Reagent kits (Applied Biosystems, Applera, Warrington, Cheshire, UK). . Real-Time PCR was performed for SULT2A1 cDNA and ribosomal 18S RNA using pre-validated Assay-on-Demand System reagents (Applied Biosystems). Briefly, $2 \mu \mathrm{L}$ cDNA was used as a template mixed with $1 \mathrm{X}$ universal Taqman master cocktail (Applied Biosystems) and the specific set of 1X primer/probe mixture. Duplicate reactions in 96-well plates were evaluated using an ABI Prism 7900 Sequence Detector (Applied Biosystems). The $\mathrm{C}_{\mathrm{T}}$ value obtained for the $18 \mathrm{~S}$ species was used to confirm cDNA quality and as an internal reference control for SULT2A1 expression. 18S RNA has been used routinely in our experiments with H295 cells over several years and has proved to be very reliable for quality control and normalisation purposes. 


\subsection{Statistics}

For salivary steroids the sex-dependent and daytime variations of the effects of liquorice containing and non-liquorice containing confectionery were compared using a general linear model of analysis of variance. Data for the effects of confectionery were matched for each individual. For studies of steroid synthesis and SULT2A1 expression in H295 cells, the effects of forskolin and GA were tested by analysis of variance with Neuman-Keul's correction. Results are expressed as mean values $\pm \mathrm{SE}$ and $\mathrm{P}<0.05$ was considered statistically significant.

\section{Results}

\subsection{Effects of liquorice on salivary steroid concentration}

There was no significant increase in systolic or diastolic blood pressure due to 1 week consumption of liquorice confectionery. Figure 1 and Table 1 shows that the overall effect of liquorice on salivary steroid concentrations in males and females is broadly similar. Cortisol, deoxycorticosterone, DHEA and testosterone were increased (although not significantly for cortisol in males) whereas aldosterone and cortisone were decreased. Effects on cortisol and cortisone are in line with known inhibition of $11 \beta$-hydroxysteroid dehydrogenase by liquorice and GA which are known to cause hypertension via a mineralocorticoid-dependent process. Apparent mineralocorticoid excess due to cortisol occupancy of MR is reflected by decreased aldosterone levels.

Increased DHEA and testosterone levels in response to liquorice were not expected. These effects are more prominent in the evening when cortisone levels are least affected (figure 2). Potentially testosterone increases could arise from peripheral conversion of DHEA derived from the adrenal gland. However, salivary testosterone and DHEA concentrations were 
significantly correlated only in males $(r=0.4, P=0.002$; females: $r=0.2, P=0.1)$. Increases in deoxycorticosterone, DHEA and cortisol could be explained by effects of liquorice on adrenocortical steroidogenesis, particularly as their routes of metabolism are different. Table 2 shows the effects of liquorice on free and conjugated steroids in pooled saliva from male subjects. The pattern of fractionated free steroid values was similar to that of unfractionated steroid values. Levels of DHEA and DOC conjugates were decreased by liquorice treatment; other steroid conjugates were not significantly affected.

\subsection{Effects of GA on basal and forskolin-stimulated steroidogenesis by $\mathrm{H} 295$ cells}

Responsiveness to ACTH is compromised in H295 cells although cyclic AMP-dependent signalling is preserved. Forskolin stimulates adenyl cyclase independent of ACTH receptors and was used in the present studies to stimulate steroidogenesis via cyclic AMP. Figure 3 shows that synthesis of unconjugated steroids were all stimulated by forskolin (DHEA > cortisol $>$ cortisone $>$ deoxycorticosterone $>$ aldosterone). Similar results were obtained with vasoactive intestinal peptide, an agonist with activity which is not dependent on cyclic AMP (data not shown). As expected of an adrenocortical cell line, very low levels of testosterone were detected in the medium and were unresponsive to forskolin treatment (data not shown). GA reduced both basal and forskolin-stimulated cortisone synthesis $(\mathrm{P}<0.01)$ but did not significantly affect cortisol synthesis. Basal and forskolin-stimulated DOC and DHEA synthesis were increased by GA but only effects on basal synthesis were statistically significant $(\mathrm{P}<0.01)$. Aldosterone responses to GA were not statistically significant.

\subsection{Dose dependent effects of GA on conjugation of steroids synthesized by $\mathrm{H} 295$ cells}

In the absence of GA similar amounts of DHEA and DHEAS were released by H295 cells; the degree of conjugation was not affected by forskolin (figure 4). DOC conjugation was 
approximately half that of DHEA and, in the absence of GA was slightly higher in forskolinstimulated cells. Cortisol, cortisone and aldosterone conjugation was 9.9, 30.0 and $62 \%$ respectively in unstimulated cells and was reduced by forskolin treatment $(3.3,15$ and 45\%) but not by GA either in the presence or absence of forskolin. GA caused dose-dependent decreases in the degree of DOC and DHEA conjugation in both basal and forskolinstimulated cells. Non- conjugated DHEA and especially DOC were increased by low doses of GA $(\leq 10 \mu \mathrm{M})$ commensurate with decreased conjugation. However, the total amounts of DHEA released (conjugated plus unconjugated) were inhibited by high doses of GA ( $\geq$ $25 \mu \mathrm{M})$.

\subsection{GA inhibits $11 \beta$-hydroxysteroid dehydrogenase activity in $\mathbf{H 2 9 5}$ cells}

Cortisone was markedly inhibited by GA (figure 5). The ratio of cortisone:cortisol was decreased by the lowest dose of GA $(1 \mu \mathrm{M})$ in forskolin stimulated cells $(\mathrm{P}=0.01)$ indicating that $11 \beta$-hydroxysteroid dehydrogenase activity is more sensitive to the inhibitory effects of GA than enzymes responsible for conjugation. However, the net effect of GA on cortisol synthesis due to 11HSD2 inhibition is probably negligible since, in the absence of GA, the proportion of cortisol converted to cortisone is less than $3 \%$ for unstimulated cells and less than $1 \%$ for forskolin-stimulated cells.

\subsection{GA inhibits conjugation of radiolabeled DOC and DHEA}

To confirm that GA inhibits conjugation of DOC and DHEA rather than de novo synthesis of steroids, H295 cells were incubated with either ${ }^{3} \mathrm{H}$-DHEA or ${ }^{3} \mathrm{H}-\mathrm{DOC}$. Conjugation of both steroids was inhibited partially with $3 \mu \mathrm{M}$ GA and by more than $80 \%$ with $30 \mu \mathrm{M}$ GA (figure 6). The inhibitory effects of the higher dose of GA were apparent within 4h (figure 7). 


\subsection{GA effects on conjugation are not due to inhibition of SULT2A1 gene transcription}

Previous studies have identified DOC and DHEA sulfates as conjugates that are derived principally from the adrenal gland due to the specific expression of SULT2A1. To establish whether GA effects on DOC and DHEA conjugation were due to inhibition of transcription, SULT2A1 mRNA transcript levels were measured by quantitative RT-PCR in cells treated with GA. Despite evidence of marked inhibition of steroid conjugation, SULT2A1 mRNA levels were unaffected (figure 7), suggesting that GA directly affects SULT2A1 enzyme activity.

\section{Discussion}

The effects of liquorice on salivary steroid levels are, in part, explained by the known inhibitory effects of glycyrrhetinic acid (GA) on 11ß-hydroxysteroid dehydrogenase activity (Conn et al., 1968; Farese et al., 1991; Walker and Edwards, 1994). The hypertensinogenic response to liquorice is due to a block in the conversion of active endogenous glucocorticoid hormone, cortisol, to inactive cortisone. The isoform of the enzyme responsible for this conversion, $11 \beta$ HSD2, is expressed in mineralocorticoid responsive target tissues where it serves to prevent high concentration of circulating glucocorticod hormones from binding inappropriately to mineralocorticoid receptors (MR). When 11HSD2 is inhibited, as shown by marked decrease in salivary cortisone:cortisol ratios, then glucocorticoids can cause MRdependent sodium retention, plasma volume expansion and ultimately an increase in blood pressure (Quinkler and Stewart 2003; Walker and Edwards, 1994). In the present study, liquorice did not cause hypertension perhaps because the period of treatment was too short or the dose of liquorice too small (Sigurjonsdottir et al., 2001). However, there was a decrease 
in salivary aldosterone, an indication of the suppression of the renin-angiotensin-aldosterone system (RAAS) when endogenous glucocorticoids activate MR. It should be noted that GA did not inhibit aldosterone synthesis by $\mathrm{H} 295$ cells indicating that aldosterone decreases in vivo are secondary to mineralocorticoid excess caused by other steroids. The ratio of cortisone:cortisol synthesised by $\mathrm{H} 295$ cells is low $(<0.02)$ and was reduced even further by GA. Assuming that endogenous adrenocortical production similarly favours cortisol over cortisone, it seems likely that the much higher cortisone to cortisol ratios in saliva reflect the effects of GA on extra-adrenal glucocorticoid metabolism.

Liquorice also caused increases in salivary DOC, DHEA and testosterone which may have additional pharmacological consequences. Firstly DOC is recognised as a weak mineralocorticoid and could, therefore, contribute to hypertensinogenic processes and suppression of RAAS. Secondly, increased DHEA and testosterone could have androgenic effects. This observation supports claims that liquorice promotes increases in muscle mass (www.bodybuilder.com/store/now/lic/html; www.crticalbench.com/licorice-root-supplementreview.htm) . It should be noted, however, that others have reported that GA binds to the androgen receptor and could, therefore, exert more direct effects (Tamaya et al., 1986).

The mechanism responsible for increases in DOC, DHEA and testosterone are not immediately apparent. None of them could be considered substrates for 11HSD2 although androgen and DOC metabolites are antagonists of 11HSD activity (Morris et al., 2007). Three possible explanations are suggested: (i) GA has been shown to inhibit two hepatic enzymes (3ß-hydroxysteroid dehydrogenase and steroid $5 \beta$ reductase) responsible for ring A reduction of steroid hormones (Latif et al., 1990). This could prolong the plasma half life of DOC and testosterone. However, aldosterone and cortisone are also catabolised by this route yet are present at lower not higher concentrations in saliva after liquorice treatment; (ii) GA could affect de novo androgen biosynthesis. It has been suggested that 11HSD1 activity modulates 
the inhibitory effects of glucocorticoids on testosterone synthesis by the Leydig cells of the testis (Hu et al., 2008; Monder et al., 1994). If GA were to inhibit the capacity of 11HSD1 to regenerate active glucocorticoid hormone, this would lessen the effects of glucocorticoids on androgen production. Against this hypothesis is the fact that the 11HSD1 enzyme is less susceptible to GA inhibition than 11HSD2 (Latif et al., 1997; Marandici and Monder, 1993) and is thought to contribute to dehydrogenase activity in Leydig cells (Ge et al., 2005). Also in the present study, effects of liquorice on salivary androgens were seen in both males and females in the presence of higher cortisol levels; (iii) GA may directly affect adrenal androgen production. In primates, DHEA and its sulfate are derived predominantly from the adrenal gland with males producing slightly more than females (Labrie et al., 2003). DHEA is converted to testosterone by peripheral tissues. To test this third possibility, we measured steroidogenesis in $\mathrm{H} 295$ cells treated with GA. H295 cells are a multipotent adrenal cell line which synthesise DHEA, DOC, cortisol and cortisone and aldosterone. A preliminary study confirmed that the profile of steroids by these cells in response to GA (figure 3) was similar to those of saliva after feeding liquorice except that testosterone levels were very low and unresponsive to trophic factors and did not respond consistently to GA. We were aware however, that GA induced changes reflected free steroid levels and did not take account of the very high levels of conjugated steroids that are synthesised by the adrenal cortex and by H295 cells. In particular, it is known that pregnenolone, 17-hydroxypregnenolone, deoxycorticosterone and DHEA are secreted as sulfates (Rainey et al., 2002; Strott, 2002).

The effects of GA on conjugated and free steroid production were tested in basal and stimulated H295 cells. Conjugated DHEA and DOC were decreased in a dose dependent manner whereas free DHEA and DOC were increased by $10 \mu \mathrm{M}$ GA. In contrast, the increase in total cortisol caused by $10 \mu \mathrm{M}$ GA was related to inhibition of $11 \mathrm{HSD}$ activity since cortisone was decreased and cortisol conjugation was unaffected. High doses of GA (> 
$50 \mu \mathrm{M})$ tended to reduce synthesis of total DHEA and increases in DOC and cortisol appeared to have reached a plateau. Arguably this high dose effect could be a non-specific toxic effect although there were no signs of cell death. An alternative possibility is that GA inhibits the sulfation of pregnenelone, a known substrate of adrenal sulfotransferase activity and an early intermediate in glucocorticoid biosynthesis. This would shunt steroidogenesis towards the synthesis of DOC and could also contribute to the amounts of basal and forskolin stimulated total cortisol release that were increased by GA (figure 5).

Previous studies have identified DOC and DHEA conjugates in the circulation as sulates. Both liver and adrenal glands express SULT2A1, an enzyme that has the activity to sulfonate both steroids (Richies et al, 2009). However, tracer studies indicate these sullates are synthesised by the human adrenal gland rather than the liver (Casey and MacDonald, 1983; Labrie, 1991); hepatic SULT2A1 appears to be responsible for the disposal of xenobiotics (Senggunpai, Yoshina and Yamazoe, 2009). The known specificity of SULT2A1 and its expression in $\mathrm{H} 295$ cells indicate that this enzyme is responsible for DOC and DHEA sulfation in these cells and is therefore a likely target of GA. The inhibition of steroid sulfation by GA appears to be a direct effect on enzyme activity rather than a decrease in SULT2A1 gene expression. Conjugation of radiolabeled DOC and DHEA was reduced $8 \mathrm{~h}$ after addition of GA at a concentration which did not affect SULT2A1 mRNA expression. Others have also reported a disparity between SULT2A1 activity and gene expression and in H295 cells. Kumar et al (2009) showed that testosterone and insulin treatment caused a marked inhibition of DHEA sulfation despite a three fold increase in SULT2A1 expression. In our experiments we suggest that GA is a competitive inhibitor of SULT2A1 activity and its effects are therefore independent of transcriptional or translational control. 
The effects of GA in vitro on H295 cells may differ from those expected in the adrenal gland in vivo. SULT2A1 is uniformly expressed by $\mathrm{H} 295$ cells so that an increase in free steroid availability caused by inhibition of conjugation will provide substrate for alternative competing enzymes. In contrast adrenal SULT2A1 levels vary at different stages of life and are localised to specific regions of the cortex (Rainey et al., 2002). In adulthood, for example, plasma DHEAS levels are highest at age 20-30 years and SULT2A1 expression are localised predominantly in the zona reticularis. Given that mineralocorticoids, glucocorticoids and androgens are produced by different zones of the cortex, it follows that GA effects on salivary steroid levels may reflect zone-specific effects on different steroidogenic enzymes

\section{Conclusions}

We have demonstrated that liquorice increases salivary DHEA, DOC and testosterone levels as well as showing expected inhibition of cortisol to cortisone conversion. In vitro analysis of steroidogenesis by $\mathrm{H} 295$ cells treated with GA show that in vivo DHEA and DOC effects are probably due to inhibition of steroid conjugation by the adrenal gland. Although these GA effects are not caused by changes in the transcription of SULT2A1 (the enzyme responsible for DOC and DHEA sulfation), it seems clear that the control of SULT2A1 activity, whether genomic or non-genomic, plays an important part in directing pathways of mineralocorticoid, glucocorticoid and androgen biosynthesis.

\section{Disclosure statement}

The authors have nothing to disclose. 


\section{Conflict of interest statement}

The authors have declared no conflict of interest.

\section{Acknowledgements}

CJK is supported by a British Heart Foundation Centre of Research Excellence award. Funds for the development and validation of assays were provided by an MRC Program Grant awarded to CJK and by the World Anti-doping Agency to EAD. None of the funding bodies had any involvement in study design, in the collection, analysis and interpretation of data, in the writing of the report or in the decision to submit the paper for publication.

\section{References}

Al-Dujaili, E.A.S., 2006. Development and validation of a simple and direct ELISA method for the determination of conjugated (glucuronide) and non-conjugated testosterone excretion in urine. Clin Chim Acta 364, 172-179.

Al-Dujaili, E.A.S., Mullins, L.J., Bailey, M.A., Andrew, R., Kenyon, C.J., 2009a. Physiological and pathophysiological applications of sensitive ELISA methods for urinary deoxycorticosterone and corticosterone in rodents. Steroids 74, 938-944.

Al-Dujaili, E.A.S., Mullins, L.J., Bailey, M.A., Kenyon, C.J., 2009b. Development of a highly sensitive ELISA for aldosterone in mouse urine: Validation in physiological and pathophysiological states of aldosterone excess and depletion. Steroids 74, 456462

Armanini, D., Bonanni, G., Palermo, M., 1999. Reduction of serum testosterone in men by licorice. N Engl J Med 341, 1158 
Asl, M.N., Hosseinzadeh, H., 2008. Review of pharmacological effects of Glycyrrhiza sp. and its bioactive compounds. Phytother Res 22, 709-724.

Atherden, S.M., Corrie, J.M., Jones, D.B., Al-Dujaili, E.A., Edwards, C.R., 1985.

Development and validation of a direct radioimmunoassay for aldosterone in saliva. Steroids 46, 845-855.

Casey, M.L., MacDonald, P.C., 1983. Origin and production rates of deoxycorticosterone and deoxycorticosterone sulfate in men and nonpregnant women. J Clin Endocrinol Metab $56,390-392$.

Conn, J.W., Rovner, D.R., Cohen E.L., 1968. Licorice-induced pseudoaldosteronism. Hypertension, hypokalemia, aldosteronopenia, and suppressed plasma renin activity. JAMA 205, 492-496.

Conway, C.A., Law Smith, M.J., Feinber, D.R. Sharp, M.J., 2007.Raised salivary testosterone in women is associated with increase attraction to masculine faces. Horm Behav 52, 156-161

Davis, E.A. Morris, D.J., 1991. Medicinal uses of licorice through the millennia: the good and plenty of it. Mol Cell Endocrinol 78, 1-6.

Farese, R.V., Biglieri, E.G., Shackleton, C.H., Irony, I., Gomez-Fontes R., 1991. Licoriceinduced hypermineralocorticoidism. N Engl J Med 325, 1223-1227.

Ge, R.S., Dong, Q., Niu, E.M., Sottas, C.M., Hardy, D.O., Catterall, J.F., Latif, S.A., Morris, D.J., Hardy, M.P., 200511 \{beta\}-Hydroxysteroid dehydrogenase 2 in rat Leydig cells: its role in blunting glucocorticoid action at physiological levels of substrate. Endocrinology 146, 2657-2664.

Groschl, M., 2009. The physiological role of hormones in saliva. Bioessays 31, 843-852.

Hu, G.X., Lin, H., Sottas, C.M., Morris, D.J., Hardy, M.P., Ge R.S., 2008. Inhibition of 11beta-hydroxysteroid dehydrogenase enzymatic activities by glycyrrhetinic acid in 
vivo supports direct glucocorticoid-mediated suppression of steroidogenesis in Leydig cells. J Androl 29, 345-351.

Hussain, R.M., 2003. The sweet cake that reaches parts other cakes can't! Postgrad Med J 79, $115-116$.

Josephs, R.A., Guinn, J.S., Harper, M.L., Askari F., 2001. Liquorice consumption and salivary testosterone concentrations. Lancet 358 1613-1614.

Kumar, A., Magoffin, D., Munir, I., Azziz R., 2009. Effect of insulin and testosterone on androgen production and transcription of SULT2A1 in the NCI-H295R adrenocortical cell line. Fertil Steril 92, 793-797.

Labrie F., 1991. Intracrinology. Mol Cell Endocrinol 78, C113-118.

Labrie, F., Luu-The, V., Labrie, C., Belanger, A., Simard, J., Lin, S.X. Pelletier G., 2003. Endocrine and intracrine sources of androgens in women: inhibition of breast cancer and other roles of androgens and their precursor dehydroepiandrosterone. Endocr Rev 24, 152-182.

Latif, S.A., Conca, T.J., Morris D.J., 1990. The effects of the licorice derivative, glycyrrhetinic acid, on hepatic 3-alpha- and 3-beta-hydroxysteroid dehydrogenases and 5-alpha- and 5-beta-reductase pathways of metabolism of aldosterone in male rats. Steroids 55, 52-58.

Latif, S.A., Sheff, M.F., Ribeiro, C.E., Morris D.J., 1997. Selective inhibition of sheep kidney 11 beta-hydroxysteroid dehydrogenase isoform 2 activity by 5-alpha-reduced (but not 5-beta) derivatives of adrenocorticosteroids. Steroids 62, 230-237.

Lee, Y.S., Kim, S.H., Kim, J.K., Shin, H.K., Kang, Y.H., Park, J.H., Lim, S.S., 2010. Rapid identification and preparative isolation of antioxidant components in licorice. J Sep Sci 33, 664-671. 
Marandici, A., Monder C., 1993. Inhibition by glycyrrhetinic acid of rat tissue 11 betahydroxysteroid dehydrogenase in vivo. Steroids 58, 153-156.

Monder, C., Miroff, Y., Marandici, A., Hardy, M.P., 1994. 11 beta-Hydroxysteroid dehydrogenase alleviates glucocorticoid-mediated inhibition of steroidogenesis in rat Leydig cells. Endocrinology 134, 1199-1204.

Morris, DJ., Latif, S.A., Hardy, M.P., Brem, A.S., 2007. Endogenous inhibitors (GALFs) of 11 beta-hydroxysteroid dehydrogenase isoforms 1 and 2: derivatives of adrenally produced corticosterone and cortisol. J Steroid Biochem Mol Biol 104, 161-168.

Quinkler, M., Stewart, P.M., 2003. Hypertension and the cortisol-cortisone shuttle. J Clin Endocrinol Metab 88, 2384-2392.

Rainey, W.E., Carr, B.R., Sasano, H., Suzuki, T., Mason, J.I., 2002. Dissecting human adrenal androgen production. Trends Endocrinol Metab 13, 234-239.

Rainey, W.E., Saner, K., Schimmer, B.P. 2004. Adrenocortical cell lines. Mol Cell Endocrinol 22, 23-38

Richies, Z., Stanley, E.L., Bloomer, J.C., Coughtrie, M.W., 2009. Qualitiative evaluation of the expression and activity of five major sulfotransferases (SULTs) in human tissue: the SULT “pie”. Drug Metab and Disp 37, 2255-2261.

Senggunprai, L., Yoshina, K., Yamazoe, Y., 2009. Selective role of sulfotransferase 2A1 (SULT2A1) in the N-sulfoconjugation of quinolone drugs in humans. Drug Metab and Disp 37, 1711-1717.

Shibata, S., 2000. A drug over the millennia: pharmacognosy, chemistry, and pharmacology of licorice. Yakugaku Zasshi 120, 849-862.

Sigurjonsdottir, H.A., Franzson, L., Manhem, K., Ragnarsson, J., Sigurdsson, G., Wallerstedt, S., 2001. Liquorice-induced rise in blood pressure: a linear dose-response relationship. J Hum Hypertens 15, 549-552. 
Strott, C.A., 2002. Sulfonation and molecular action. Endocr Rev 23, 703-732.

Takahashi, K., Yoshino, K., Shirai, T., Nishigaki, A., Araki, Y., Kitao, M., 1988. Effect of a traditional herbal medicine (shakuyaku-kanzo-to) on testosterone secretion in patients with polycystic ovary syndrome detected by ultrasound. Nippon Sanka Fujinka Gakkai Zasshi 40, 789-792.

Takeuchi, T., Nishii, O., Okamura, T., Yaginuma, T., 1991. Effect of paeoniflorin, glycyrrhizin and glycyrrhetic acid on ovarian androgen production. Am J Chin Med 19, 73-78.

Tamaya, T., Sato, S. \& Okada, H., 1986. Inhibition by plant herb extracts of steroid bindings in uterus, liver and serum of the rabbit. Acta Obstet Gynecol Scand 65, 839-842.

Walker, B.R., Edwards, C.R., 1994. Licorice-induced hypertension and syndromes of apparent mineralocorticoid excess. Endocrinol Metab Clin North Am 23, 359-377.

www.bodybuilder.com/store/now/lic/html

$\underline{\text { www.criticalbench.com/licorice-root-supplement-review.htm }}$ 


\begin{tabular}{|l|c|c|c|c|c|}
\hline Steroid & $\begin{array}{c}\text { Liquorice } \\
\text { treatment }\end{array}$ & $\begin{array}{c}\text { Sample } \\
\text { Time }\end{array}$ & Sex & $\begin{array}{c}\text { Treatment } \\
\text { *Sample time }\end{array}$ & $\begin{array}{c}\text { Treatment } \\
\text { *Sex }\end{array}$ \\
\hline DHEA & 0.0005 & 0.4 & 0.01 & 0.02 & 0.9 \\
\hline DOC & 0.0005 & 0.4 & 0.0005 & 0.4 & 0.7 \\
\hline Cortisol & 0.0005 & 0.2 & 0.0005 & 0.7 & 0.001 \\
\hline Cortisone & 0.03 & 0.0005 & 0.001 & 0.2 & 0.8 \\
\hline Aldosterone & 0.03 & 0.93 & 0.001 & 0.8 & 0.5 \\
\hline Testosterone & 0.0005 & 0.06 & 0.0005 & 0.1 & 0.7 \\
\hline
\end{tabular}

Table 1. Probability values for effects of liquorice, time of sampling and sex on salivary steroid levels. Also shown are values for interactions between treatment and sample time and treatment and sex. There were no significant differences for a three way interaction between treatment, sample time and sex. 


\begin{tabular}{|l|c|c|c|c|c|c|}
\hline \multirow{2}{*}{ Steroid } & \multicolumn{3}{|c|}{ Free Fraction (nM) } & \multicolumn{3}{c|}{ Conjugated Fraction (nM) } \\
\cline { 2 - 7 } & Non-liquorice & Liquorice & P value & Non-liquorice & Liquorice & P value \\
\hline DHEA & $7.6 \pm 3.4$ & $17.6 \pm 5.5$ & 0.001 & $2.2 \pm 0.6$ & $1.3 \pm 0.3$ & 0.03 \\
\hline DOC & $0.23 \pm 0.04$ & $0.32 \pm 0.05$ & 0.02 & $0.75 \pm 0.08$ & $0.6 \pm 0.09$ & 0.01 \\
\hline Cortisol & $17.8 \pm 2.8$ & $22.9 \pm 3.3$ & 0.01 & $10.7 \pm 1.9$ & $12.2 \pm 1.6$ & 0.2 \\
\hline Cortisone & $0.62 \pm 0.12$ & $0.34 \pm 0.06$ & 0.01 & $0.15 \pm 0.04$ & $0.13 \pm 0.03$ & 0.6 \\
\hline Aldosterone & $0.11 \pm 0.01$ & $0.06 \pm 0.01$ & 0.02 & $0.08 \pm 0.01$ & $0.07 \pm 0.01$ & 0.2 \\
\hline Testosterone & $0.82 \pm 0.08$ & $1.03 \pm 0.14$ & 0.05 & $2.39 \pm 0.33$ & $2.61 \pm 0.05$ & 0.3 \\
\hline
\end{tabular}

Table 2. Effects of liquorice on free and conjugated salivary steroid levels from male volunteers. Saliva samples $(0.5 \mathrm{ml})$ collected at $09.00,12.00$ and $19.00 \mathrm{~h}$ were pooled and fractionated with Sep-Pak C18 cartridges as described in the methods section. Conjugated steroids were hydrolysed with Helix pomatia prior to assay. Results are means $\pm \mathrm{SEM}$. 


\section{Figure Legends}

Figure 1: Changes in salivary steroid levels in men and women in response to liquorice. Values shown are means \pm SEM of the percentage change in salivary steroid levels after feeding liquorice to groups of ten men (open bars) and ten women (solid bars) compared with pre-treatment control values. Values for each individual from samples collected on three separate occasions have been averaged for the non-liquorice and for the liquorice arms of the study. Average values with liquorice treatment are expressed as a percentage of average nonliquorice values. Significant effects of liquorice are indicated as * $-\mathrm{P}<0.05 ; * *-\mathrm{P}<0.01, * * *$ $\mathrm{P}<0.001$.

Figure 2: Salivary steroid levels throughout the day with non-liquorice confectionery (open circles) and liquorice confectionery (solid circles). Values shown are means \pm SEM of twenty volunteers (10 men, 10 women).

Figure 3: Effects of glycyrrhetinic acid on steroidogenesis in $\mathrm{H295}$ cells incubated with and without forskolin.. Medium from H295 cells cultured for $24 \mathrm{~h}$ with and without $10 \mu \mathrm{M}$ GA and with and without $10 \mathrm{mM}$ forskolin were analysed for unconjugated steroid hormone levels by ELISA. Results $(n=4$, mean \pm SEM) are expressed as fold differences relative to controls.

Figure 4: Concentration-dependent effects of glycerrhetinic acid on DOC and DHEA conjugation by $\mathrm{H} 295$ cells incubated with (open circles) and without (solid circles) forskolin. Results are measurements of unconjugated and conjugated DOC and DHEA levels in culture medium of $\mathrm{H} 295$ cells incubated for $24 \mathrm{~h}$ with and without $10 \mathrm{mM}$ forskolin in the 
presence of increasing concentrations of GA $(n=4$, mean \pm SEM). Percentage conjugation $=$ $\%$ (conjugate) / (conjugate + unconjugated) values.

\section{Figure 5: Concentration-dependent effects of glycyrrhetinic acid on 11ß-hydroxysteroid} dehydrogenase activity. Results are measurements of total (unconjugated + conjugated) levels in culture medium medium of $\mathrm{H} 295$ cells incubated for $24 \mathrm{~h}$ with and without $10 \mathrm{mM}$ forskolin in the presence of increasing concentrations of GA $(n=4$, mean \pm SEM). The ratio of total cortisone: total cortisol is taken as an index of net $11 \beta$-hydroxysteroid dehydrogenase activity.

Figure 6:.Concentration-dependent inhibition of radiolabeled DOC and DHEA conjugation by glycyrrhetinic acid. $\mathrm{H} 295$ cells were incubated for $24 \mathrm{~h}$ with ${ }^{3} \mathrm{H}$ DOC or ${ }^{3} \mathrm{H}$ DHEA in the presence of increasing concentrations of GA. The culture medium of each sample was fractionated using Sep-Pak C18 cartridges and radioactivity associated with free or conjugated fractions was counted. Percentage conjugation $=\%$ (radioactivity of conjugate fraction) / (radioactivity of conjugate + unconjugate fractions). Results are means $\pm \mathrm{SEM}$, $\mathrm{n}=4$. Significant effects of GA compared with controls are indicated as * $-\mathrm{P}<0.05$; ** $\mathrm{P}<0.01$.

Figure 7: Temporal effects of glycyrrhetinic acid on DHEA conjugation and SULT2A1 mRNA expression by $\mathbf{H 2 9 5}$ cells. DHEA conjugation was measured using radiolabeled DHEA (see figure 6) in medium collected at intervals after addition of $30 \mu \mathrm{M}$ glycyrrhetinic acid to H295 cells. RNA extracted from cells at these time points were used to quantify SULT2A1 mRNA $(\mathrm{n}=4$, mean \pm SEM) by real time RTPCR with results normalised with 
18S RNA levels. Significant effects of GA compared with controls are indicated as * $\mathrm{P}<0.05 ; * *-\mathrm{P}<0.01$. 
Figure 1

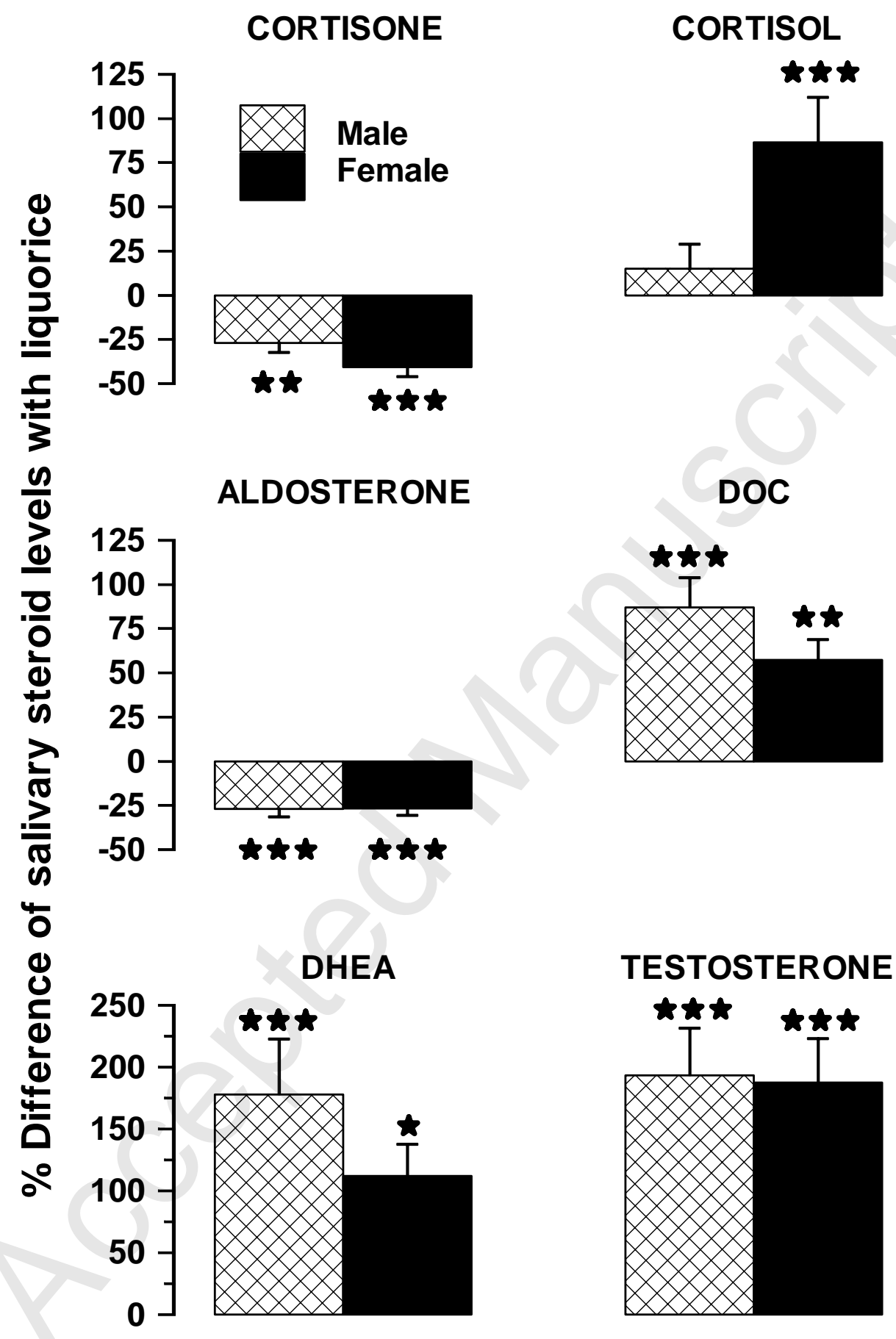


Figure 2
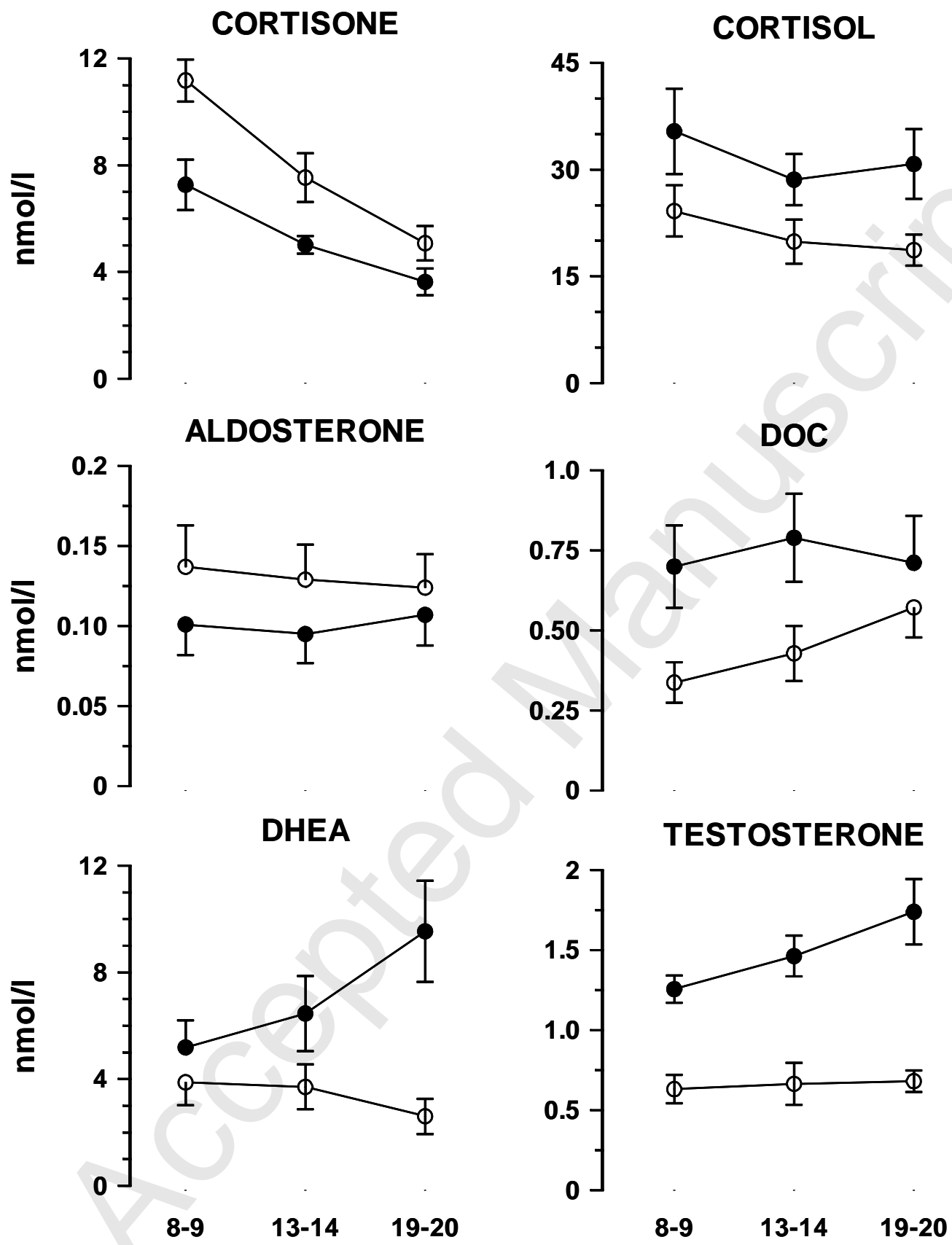

Time (h) 
Figure 3

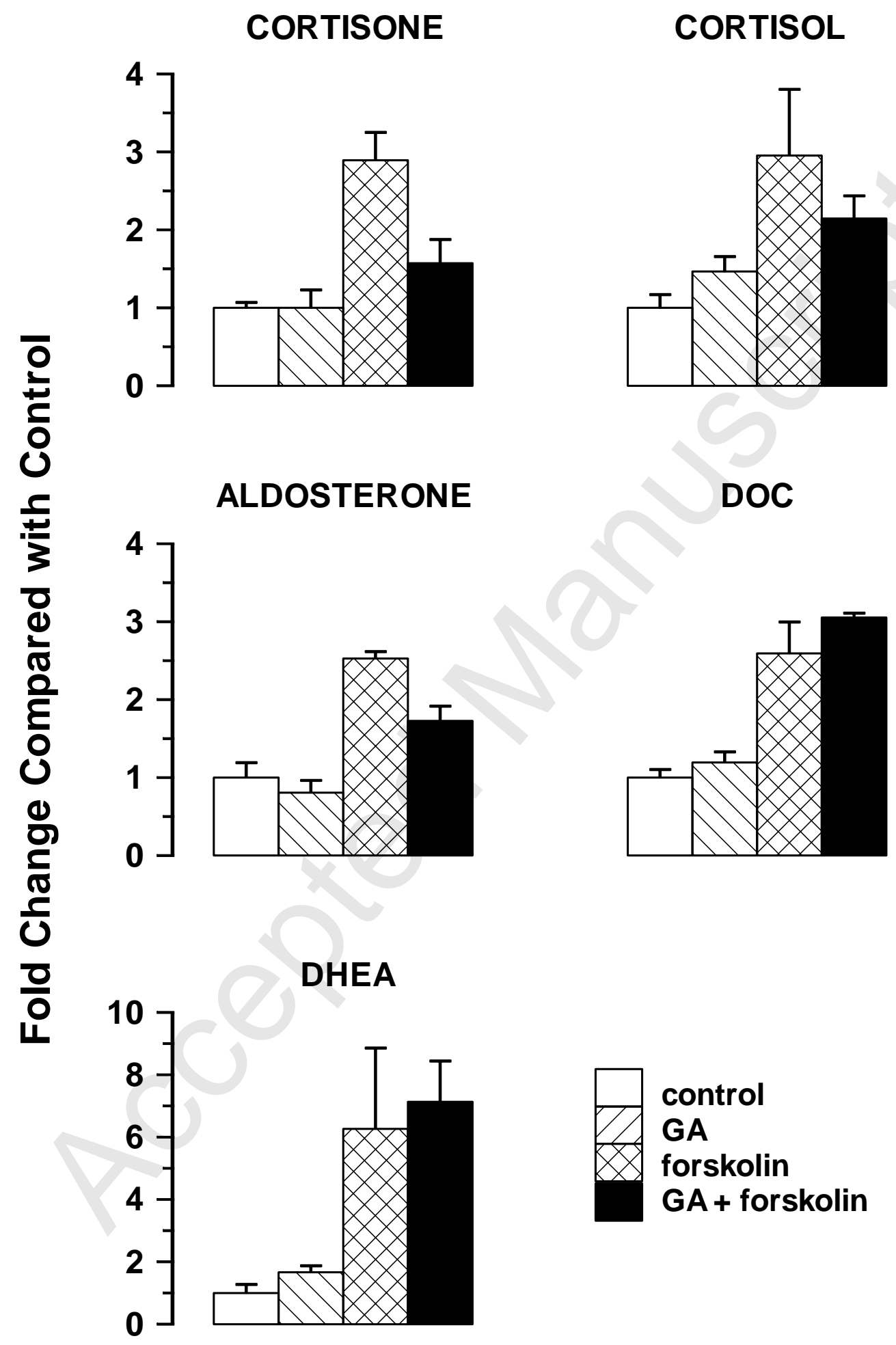


Figure 4
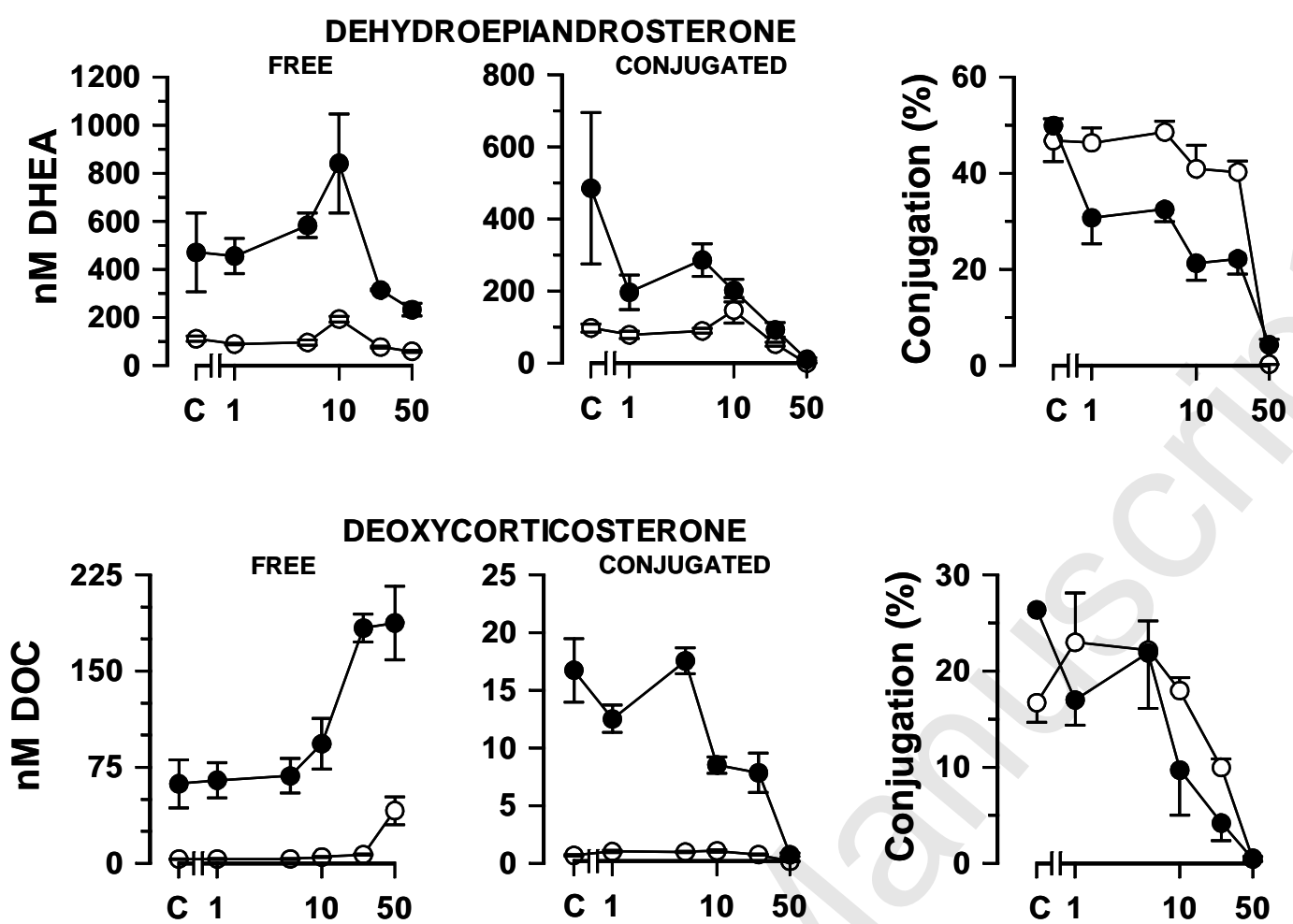

Glycyrrhetinic acid $(\mu \mathrm{M})$ 
Figure 5
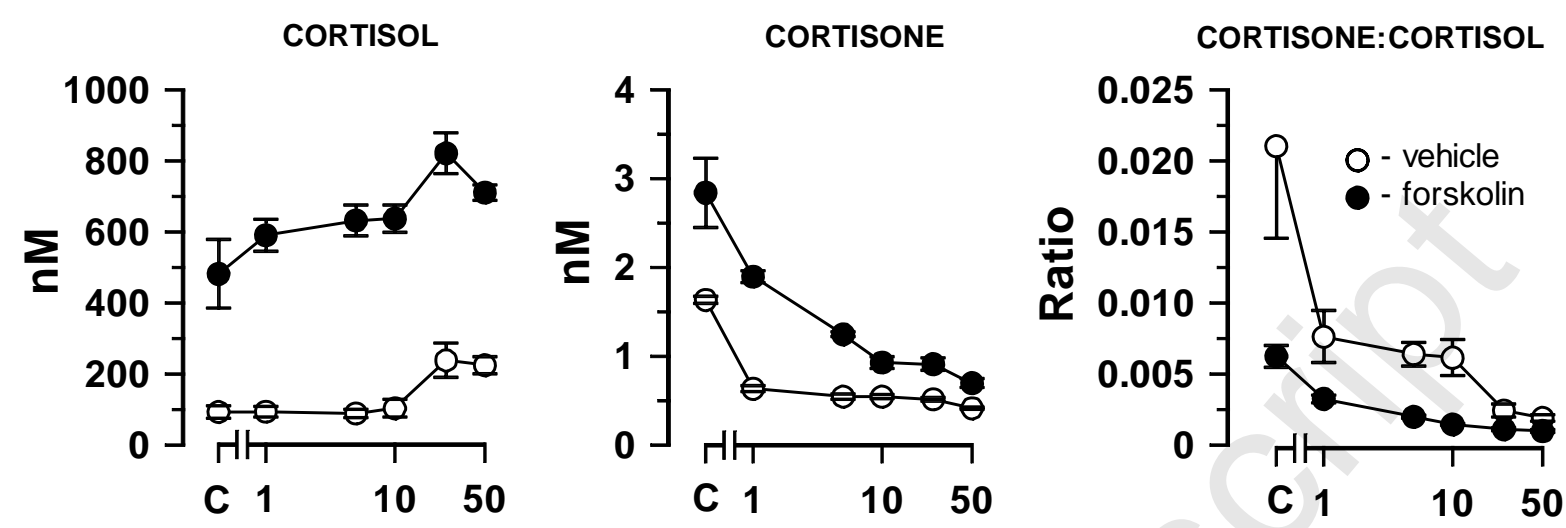

Glycyrrhetinic acid $(\mu \mathrm{M})$ 
Figure 6
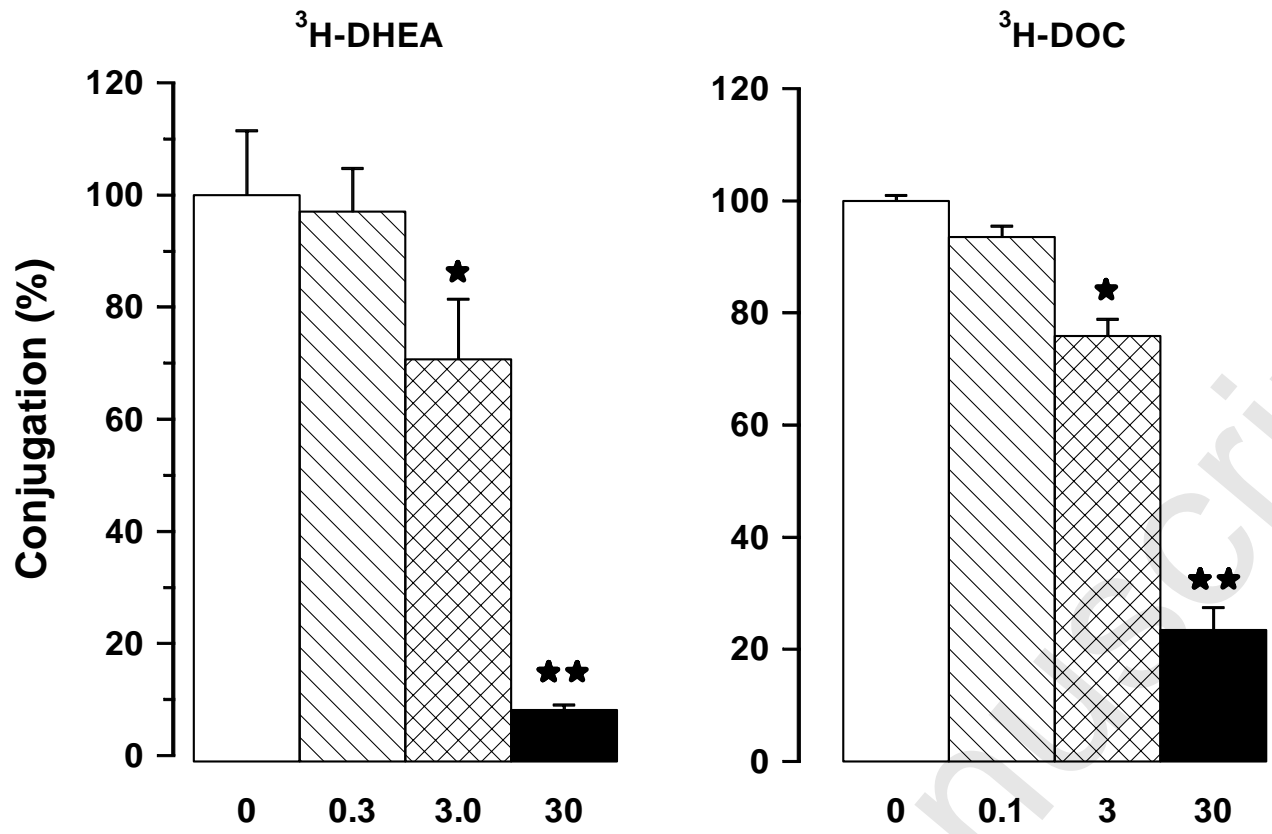

Glycyrrhetinic Acid $(\mu \mathrm{M})$ 
Figure 7

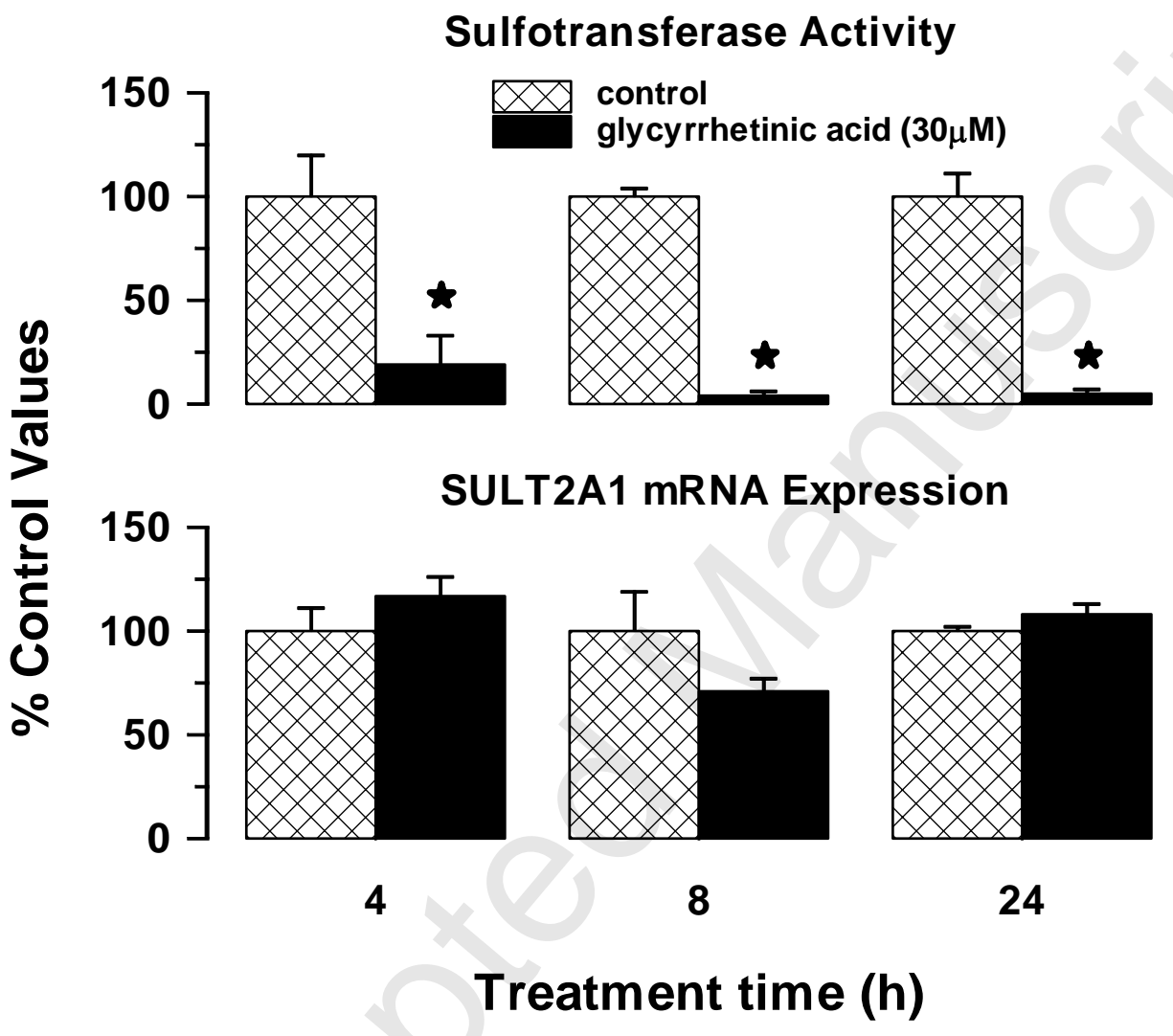

